\title{
El DCECH y los diccionarios de la Academia ${ }^{1}$
}

\author{
Gloria Clavería y Carmen Morales \\ Seminario de Filología e Informática \\ Universidad Autónoma de Barcelona
}

\section{INTRODUCCIÓN}

La labor investigadora que desde hace varios años lleva a cabo el equipo del Seminario de Filología e Informática de la UAB con la informatización del Diccionario crítico etimológico castellano e hispánico de J. Corominas y J. A. Pascual, nos ha hecho apreciar el gran valor y mérito de esta obra, sin que por ello podamos obviar las limitaciones $\mathrm{y}$ deficiencias que naturalmente se derivan de un trabajo que es fruto de un esfuerzo prácticamente individual.

Uno de los pilares fundamentales para el estudio etimológico del léxico de una lengua es la documentación de cada una de las voces en las distintas fuentes escritas (lexicográficas, textuales, dialectales, bibliográficas, etc.). Esta tarea del estudio histórico-etimológico es probablemente una de las más arduas y, a la vez, ingratas. Joan Corominas, al elaborar sus diccionarios etimológicos del español, tuvo que desarrollar este aspecto economizando esfuerzos, pues de otra manera no hubiese podido finalizar su obra con éxito. Todos los que se interesan, o se han interesado en alguna ocasión, por el estudio de cuestiones

1 La investigación necesaria para desarrollar este trabajo ha sido parcialmente financiada con una ayuda de la DGICYT para el proyecto "Informatización y actualización del $D C E C H$ de J. Corominas y J. A. Pascual" ( ${ }^{\circ}$ de referencia PB98-0884) y con el apoyo del Comissionat per Universitats i Recerca de la Generalitat de Catalunya $\left(\mathrm{n}^{\circ}\right.$ de referencia $\left.1999 \mathrm{SGR} 0114\right)$. 
de lexicología, tanto sincrónicas como diacrónicas, conocen la importancia de los datos y la necesidad de un acopio importante de estos para poder desarrollar la más mínima investigación.

El inmenso esfuerzo que se oculta detrás de cualquier obra lexicográfica es bien conocido por todos aquellos que han vivido de cerca la elaboración de un diccionario, a pesar de ello resulta muy fácil criticar este tipo de obras desde múltiples perspectivas, pues por sus mismas características, se prestan a las más variadas censuras. En este sentido, cabe recordar que la información documental del $D C E C H$ ha valido a su autor algunas críticas y muchas adiciones a la información que contiene la obra (Blecua y Clavería 1999; Clavería 1999b).

En un artículo reciente (Blecua y Clavería 1999), se ha estudiado una pequeña muestra de las fuentes que emplearon los autores del $D C E C H$. Dicha muestra se realizó teniendo en cuenta los materiales que atesora el diccionario para la documentación de las voces en las letras A y S (más de 7500 referencias documentales). Una de las primeras observaciones que se desprende de su análisis es el notable peso de los datos procedentes de obras lexicográficas: glosarios, vocabularios y diccionarios que por pertenecer a épocas pasadas recogen más o menos fielmente la pervivencia de la voz estudiada en una época concreta. El porcentaje de estas fuentes es superior al $22 \%$ en la letra A y llega hasta el 34\% en la letra S (Blecua y Clavería 1999: 36).

Dentro de las fuentes lexicográficas destacan las diversas ediciones del Diccionario de la Academia, desde el Diccionario de Autoridades hasta la edición de 1936-1939, que fue la última que consultó J. Corominas. El mismo autor aclara que la edición de "1947 ya no pudo ser utilizada en el DCEC" (DCECH, p. XXXVIII). La importancia de las documentaciones procedentes de los diccionarios académicos puede percibirse en la muestra a la que antes se ha aludido; dentro de ella, la documentación académica representa, para la letra $\mathrm{A}$, un $8 \% \mathrm{y}$, para la letra S, un $11.8 \%$. En general, la aparición de los vocablos en las diversas ediciones de los diccionarios elaborados por la Corporación fue tenida en cuenta sobre todo para la documentación del vocabulario más 
moderno, y también se recurre a ella para seguir los avatares del léxico del español desde el siglo XVIII hasta la actualidad.

El modus operandi seguido por J. Corominas se explicita en las páginas dedicadas a las "Referencias bibliográficas", en las que en la entrada Acad. se detallan las ediciones que manejó: la segunda, publicada en 1783; la quinta, de 1817; la novena, de 1843; la undécima, de 1869; la duodécima, de 1884; la decimotercera, de 1899; la decimocuarta, de 1914; la decimoquinta, de 1925; y, por último, la decimosexta, de 1936. No emplea en su diccionario ni la tercera (1791), ni la cuarta (1803), ni la sexta (1822), ni la séptima (1832), ni la octava (1837), ni tampoco la décima $(1852)^{2}$. La falta de exhaustividad en sus consultas explica que se adopten unas fórmulas características para indicar que se ha hallado la voz estudiada en una de las ediciones académicas y no se la encuentra en la edición anterior consultada, que no necesariamente es la edición precedente. Las fórmulas que indican este tipo de información suelen adoptar las siguientes redacciones:

$\begin{array}{ll}\text { farruco } & \text { Acad. 1884, no } 1843 \\ \text { galbana } & \text { Acad. 1817, no } 1783 \\ \text { galena } & \text { Acad 1843, no } 1817 \\ \text { lairén } & \text { Acad. ya 1869, no } 1843 \\ \text { meandro } & \text { Acad. ya 1914, no 1884 } \\ \text { monserga } & \text { Acad. ya 1843 (no 1832) }\end{array}$

En otros casos no se comparan dos ediciones del diccionario académico, únicamente se da una documentación provisional de su primera aparición en los diccionarios de la Corporación:

babazorro

balate, II

escarrio

farota
Acad. ya 1817

falta aún Acad. 1884

Acad. después de 1899

en Acad. 1843

2 Sin embargo, en algunas voces menciona estas ediciones. 


$\begin{array}{ll}\text { mesticia } & \text { Acad. s. XX } \\ \text { miriñaque } & \text { Acad. 1869 o } 1852 \\ \text { mildeu } & \text { Acad. } 1925 \text { o } 1936 \\ \text { paco (s.v.farruco) } & \text { Acad. 1914 o } 1899\end{array}$

Este aprovechamiento parcial de las diferentes ediciones del DRAE motiva que una parte importante de las informaciones del DCECH procedentes de los diccionarios de la Academia sea sólo indicativa y encierre un grado de inexactitud, o de provisionalidad, más o menos elevado según el caso. Ello se ve agravado por el hecho de que en algunas ocasiones es la única información que se aporta para trazar la historia documental de la palabra. Por ejemplo, en cabila y cacatúa aparece como primera documentación "falta aún Acad. 1884"; en cicerone, cifosis, eczema, elfo, enzima, "falta aún Acad. 1899"; en condón, "falta aún Acad. 1936-9". Todos estos ejemplos tienen como única datación una información negativa que no puede constituirse en primera documentación.

Las indicaciones de este tipo son relativamente frecuentes tanto en el apartado de la primera documentación como en la parte del artículo en la que se describe la historia documental de la voz.

\section{LA INFORMACIÓN DOCUMENTAL EN EL PROYECTO DE INFORMATIZACIÓN DEL DCECH}

Al llevar a cabo la informatización de los datos documentales del $D C E C H$, se tuvieron en cuenta todas las peculiaridades que este tipo de información presentaba en el diccionario etimológico. En un primer estadio de simple trasvase de información del diccionario a soporte informático, se diseñó una base de datos constituida por una ficha para cada documentación. La estructura de esta recoge todas las informaciones que pueden aparecer en una fuente documental:

LEMA

SUB VOCE

PRIMERA DOCUMENTACIÓN 


\section{FECHA}

\section{AUTOR \\ OBRA \\ EJEMPLO \\ REFERENCIA}

La información FECHA resulta de vital importancia para la ordenación cronológica de todas las documentaciones de una palabra. En PRIMERA DOCUMENTACIÓN se indica si la ficha que se consulta es la primera datación dada por el Diccionario. En AUTOR aparece, si lo hay, el nombre del autor de la obra citada. En OBRA aparece el título de la fuente. En EJEMPLO consta, siempre que el $D C E C H$ recoge este dato, la forma concreta del lema en los textos o, incluso, un pequeño fragmento si así lo presenta el Diccionario. Finalmente, en REFERENCIA se incluye información sobre la edición de la obra que se ha consultado, en el caso de que se mencione.

Con el mero traslado de informaciones del Diccionario a la base de datos, se ha obtenido un producto que es su fiel reflejo pero que, como éste, está repleto de inexactitudes e irregularidades. Estas pueden ser de varios tipos: ausencia de algún dato (fecha, obra o autor); heterogeneidad al citar diversas ocasiones un mismo documento o un mismo autor; información provisional como la que se ha analizado en el caso de los diccionarios de la Academia, etc.

En una segunda fase de la informatización (actualmente en curso), se está homogeneizando todo el material contenido en nuestras bases de datos (48.000 fichas con información documental). En el caso de las documentaciones procedentes de las distintas ediciones del DRAE, con la ayuda del programa Buscón, es posible completar y añadir las fechas exactas de documentación de una forma muy rápida. Con ello, las dataciones basadas en los diccionarios de la Academia adquieren la exactitud que J. Corominas no pudo otorgarles. No ignoramos que la historia de una palabra no puede construirse únicamente con documentaciones de origen lexicográfico (Clavería 1993), pues, para el léxico más moderno y dado el carácter normativo del Diccionario de 
la Academia, lo normal es que estas voces se encuentren documentadas con anterioridad en los textos de tema especializado; sin embargo, la datación en los diccionarios de la Academia constituye un dato importante en la historia de la palabra dado el carácter normativo del léxico que se admite en las obras de la Corporación.

En este artículo presentamos un pequeño avance del trabajo que actualmente se está desarrollando; la muestra (v. apéndice) recoge los lemas de las letras A, B y C (primera columna), cuya primera documentación en el DCECH (segunda columna) coincide con una de las ediciones del Diccionario de la Real Academia Española ${ }^{3}$. En la tercera columna aparece, comprobada, la fecha de primera documentación en los diccionarios académicos.

Del análisis de los datos reunidos en el apéndice se deduce que J. Corominas percibió la importancia de la duodécima edición del Diccionario de la Academia, publicada en 1884, y la tomó muy frecuentemente como punto de partida en sus búsquedas documentales. Son muchas las ocasiones en las que, al contrastar la documentación que aporta el $D C E C H$ con todas las ediciones del DRAE, el dato se confirma (abducción, abomaso, abubo, acalefo, acleido, aliadas, adenitis, etc.). Estos ejemplos no hacen más que mostrar la buena intuición de J. Corominas al elegir esta edición como referente fundamental para la documentación del vocabulario moderno (compárese Alvar 1982; Battaner 1996; Lapesa 1996 y Garriga (en prensa)). En algunas voces, sin embargo, la edición de 1884 es una documentación inexacta porque el término ya se encontraba en alguna de las ediciones anteriores. Por este motivo hay que adelantar la primera documentación (lexicográfica) de 1884 a 1869 en lemas como acarralar, ajá, ajajá, aleatorio, amarraco, angaria, angazo, antílope, arcaico, autóctono, etc. A pesar de que la edición de 1869 es una de las que tiene en cuenta en la documentación de las voces de su diccionario, se puede observar en estos ejemplos como se utiliza la edición de 1884, más que cualquier otra,

3 No hemos incluido los lemas cuya primera documentación, según el $D C E C H$, se encuentra en el Diccionario de Autoridades. 
como inicio de la búsqueda. En otras voces, la documentación de 1884 se puede adelantar bastante más; las dataciones de acipado, aladroque, ambleo, andaraje, aniaga, antidoral, arandillo o bayoco, hasta 1770; las de anuente, baritono, calabre o cálido II, hasta 1780; las de alboheza o azagador, hasta 1803; las de albaida, alfazaque, alferraz o algavaro, hasta 1817; la de cartolas, hasta 1822; la de arroaz, hasta 1832; la de bimembre, hasta 1837; la de alisios, hasta 1843 y la de cloro, hasta 1852.

No hay que olvidar, además, que en múltiples ocasiones la documentación proporcionada es negativa (estos casos corresponden a las fechas de la segunda columna del apéndice que van seguidas de la letra $\mathrm{F}(\mathrm{alta})$ ). También en estos ejemplos muchas veces se empieza la búsqueda en la edición de 1884. Al comprobar las informaciones académicas, se aprecia que parte de los lemas con información negativa aparece en la edición de 1899 (amperio, ánodo, artocárpeo, azoleo butomeo, cabila, cacatúa, coque); otros, en la de 1914 (aceguero, albarrada I, analgesia, atresia, avetoro, bargueño, chancro); otros, en la de 1925 (abobra, amuso, angioma, betijo, brasca, brilla, cacodilo, calamistro, cambrillón, calántica, carló, casida, casitéridos); otros, en la misma edición de la que partía J. Corominas, la de 1936 (acrídido, anacoluto, autarquía, buganvilla, bugle, cestodos). Aunque en menor medida, se utiliza también la edición de 1899 para las documentaciones negativas (ácrata, acroamático, aedo, berlanga, bornizo, boxear, chalet, caqui, cicerone, cicindela, cifosis, cinglar, clan, clarens, clica, cobez, coco III, codón, cola III, colimación, colla, comto, connivente, cormiera, corónide, crátera, crecal, crematístico, cricoides, cuasia, cuché, cucuiza, culícidos); en esta última también se producen notables incorporaciones léxicas (Clavería 1999b), por lo que es muy posible que en muchos casos, después de consultar sin éxito la edición de 1884, el autor hiciese lo mismo con la edición siguiente, aunque también sin obtener resultado. De las informaciones negativas basadas en la edición de 1899, la gran mayoría de ellas aparece por primera vez en 1925 (aedo, caqui, cicindela, cifosis, clan, claren, cobez, cola III, comto, cormiera, crátera, crecal, crematístico, cuasia, cucuiza), el resto aparece en la edición de 1914 (ácrata, acroamático, 
berlanga, bornizo, cinglar, colla) o en las ediciones posteriores a 1925.

Se puede observar, por tanto, como las dos ediciones de finales del siglo XIX son dos de las piezas fundamentales de la documentación del $D C E C H$, junto con el llamado Diccionario de Autoridades, que Corominas también usó ampliamente.

Existen, además, otras voces en las que las investigaciones realizadas permiten avanzar las fechas de la Academia con respecto a otras ediciones diferentes a 1884 ó 1899 . Tal es el caso de acarrarse, que de 1780 puede adelantarse a 1770; las voces comistrajo, comiza, cotofre, de 1783 a 1780; borda, de 1817 a 1770; coca II y codena, de 1817 a 1780; baga I, de 1817 a 1803; cuñete, de 1843 a 1780; curul, de 1843 a 1803; cuarzo, de 1843 a 1817; cúspide, de 1843 a 1832; cúter, de 1843 a 1837; alifa, de 1869 a 1817; astracán, de 1925 a 1914.

Se confirma la documentación de acotar y braznar (1780); arta (1817); cereal (1822); cerámica (1869); casuario, cícero, cingleta, ciperáceo, cistíneo, cladodio y cleda (1899); argo, batómetro y coñac (1914); apache, canterio y celán (1925); y arbequín, aspirina y batimetría (1936).

En un grupo de voces, el $D C E C H$ proporciona dos fechas como margen de su primera documentación en la Academia (la primera negativa y la segunda positiva). El buen criterio de J. Corominas vuelve a ponerse de manifiesto al coincidir la comprobación de los datos con la segunda de las documentaciones aportadas (es decir, con la información positiva). Así ocurre en branquia (1832F-1884), documentada efectivamente en esta última edición; o en las voces capuana, civeta, colofón, coma II, coma IV, concia, cora, cornaca, coruscar, cosmos, cotillón, cran, cremación, cremallera, creosota, cretino, cretona, cric, crup, cuchipanda, a las que les ocurre lo mismo y cuya documentación negativa es de 1843. En otros casos, el margen cronológico sirve sólo de orientación: cráter y croquis $(1817 \mathrm{~F}-1843 \mathrm{Y})$ aparecen en 1832; cohobar, coleóptero, comodoro, cóndilo, consola, corimbo, corindón, cromo (1843F-1884Y) se documentan en 1869. Finalmente, coy aparece con la datación "Acad. ya 1843, no 1817", cuando en re- 
alidad la palabra ya figuraba en la edición de 1791 bajo la variante gráfica coi, que en 1832 es sustituida por la forma coy. En los ejemplos precedentes se puede observar que Corominas empleó la edición de 1843 repetidamente, aunque sin mucho éxito, con el fin de adelantar la documentación de la palabra que hallaba en la edición de 1884 (Morales 2000).

En el caso de acre (sustantivo) se da como primera documentación "Ya Acad. 1884", pero el término no aparece hasta la edición de 1899; seguramente se produjo una confusión con acre (adjetivo) que sí constaba en la edición mencionada. En la voz cicerone (s. v. cícero) 'persona que enseña y explica las curiosidades de una localidad, edificio, etc.' se indica que "falta aún Acad. 1899"; la palabra, en realidad, tiene una agitada historia documental en la tradición académica, pues se encuentra ya en la edición de 1869 , desaparece en las ediciones de 1884 y 1899, y se vuelve a recoger definitivamente en 1914.

Ni bacilo ni bacteria se encuentran en el DRAE de 1899, como aparece en el $D_{C E C H}$; habrá que esperar hasta 1914 para hallar su entrada en el Diccionario de la Academia.

Finalmente, cabe detenerse en el ejemplo de codena del que J. Corominas observa que "la existencia de este vocablo necesita confirmación. Definía la Acad. en 1817 y 1884 «en el obraje de los paños, consistencia y fortaleza que debe tener el tejido», como palabra antigua. Desapareció en la ed. de 1899, y vuelve a estar en la de 1936, con definición análoga y como término poco usado". De hecho, la voz codena aparece en el diccionario académico desde 1780, desaparece en las ediciones de 1899 y 1914, y vuelve a incorporarse en 1925, tal como señala J. Corominas, manteniéndose hasta la edición de 1992.

Resulta interesante la historia de andullo en la lexicografía académica y su contraste con la información del $D C E C H$ : este diccionario documenta por primera vez la voz en la edición de 1770 señalando: "Acad. 1770, con la indicación «en algunas partes se llama así al pandero»". La documentación en este caso es correcta, pero sorprende, al contrastar los datos del DCECH con los de la Academia, el hecho de que J. Corominas y J. A. Pascual distingan la acepción 'tamarindo envuelto 
en hojas de plátano' que no aparece en ningún momento de la dilatada tradición académica. Esta acepción procede del Diccionario histórico de la lengua española (1933-1936), en el que aparece desprovista de documentación. Se plantea con este ejemplo un tema muy interesante para la crítica sobre la labor etimológica y lexicográfica de J. Corominas que consiste en el aprovechamiento que hizo de los materiales de esta obra.

\section{CONCLUSIÓN}

En los diccionarios histórico-etimológicos la información documental es muy importante porque la historia de una voz puede ser construida y reconstruida a través de ella. Para que tal cosa sea factible, la documentación debe ser un buen reflejo de la historia de la voz. La información procedente de fuentes lexicográficas es importante, aunque no debe ser la única por cuanto la incorporación de una voz a los diccionarios puede producirse con cierto "retraso" con respecto a otro tipo de fuentes documentales ${ }^{4}$.

El cotejo realizado entre los datos del DCECH y las distintas ediciones del DRAE ha mostrado el buen hacer de J. Corominas en el uso de las distintas ediciones de esta obra, pero permite también ajustar a la realidad las documentaciones inexactas, con lo que el Diccionario gana en precisión y en número de datos. Lo que inicialmente podía parecer una tarea ardua e ingrata, puede realizarse en la actualidad de forma muy rápida gracias al programa Buscón.

\section{REFERENCIA BIBLIOGRÁFICAS}

ACADEMIA EsPaÑola, http://www.rae.es. Recursos de investigación, Biblioteca virtual de diccionarios académicos.

Alvar EzQuerra, Manuel (1982): "El Diccionario de la Academia en sus

4 Compárese el tratamiento de la información lexicográfica en el Diccionario histórico de la lengua española (Seco 1995). 
prólogos", en Lexicografia descriptiva, Barcelona, Biblograf, 1983, pp. 215-239.

BATTANER, M. Paz (1996): “Terminología y diccionarios”, en Jornada panllatina de terminologia. Perspectives i camps d'aplicació. 14 de desembre de 1995, Barcelona, IULA, pp. 93-117.

BlECUA, José Manuel; ClAVERÍA, Gloria (1999): "La lexicografía castellana, antes y después de Coromines", en J. Solà (ed.), L'obra de Joan Coromines. Cicle d'estudi i homenatge, Sabadell, Fundació Caixa de Sabadell, Aula de Ciència i Cultura 4, pp. 29-43.

ClaVería, Gloria (1993): "La información lexicográfica en el Diccionario crítico etimológico castellano e hispánico (DCECH) de J. Coromines y J. A. Pascual", en Gerold Hilty (ed.), Actes du XX Congrès International de Linguistique et Philologie Romanes, Tübingen und Basel, A. Francke Verlag, 1993, tome IV, pp. 591-604.

(1999a): "El léxico especializado en la lexicografía de finales del siglo XIX: la decimotercera edición (1899) del Diccionario de la Lengua Castellana de la Academia", comunicación presentada en el II Coloquio Internacional sobre la historia de los lenguajes iberorrománicos de especialidad: la divulgación de la ciencia, Institut Universitari de Lingüística Aplicada, Universitat Pompeu Fabra, Barcelona, 27-29 de mayo de 1999. Actas en prensa.

(1999b): "La documentación en el diccionario etimológico", en José Manuel Blecua et al. (eds.), Filología e informática. Nuevas tecnologías en los estudios filológicos, Editorial Milenio-UAB, Lleida, pp. 259-280.

DCECH. Corominas, Juan; Pascual, José Antonio (1980-1990): Diccionario crítico etimológico castellano e hispánico, 6 vols., Madrid, Gredos.

GARRIGA, Cecilio (en prensa): "Sobre el Diccionario académico: la $12^{\mathrm{a}}$ ed. (1884)", en A. M Medina Guerra (ed.), Lexicografia diacrónica. Conmemoración del V Centenario del Vocabularium ecclesiasticum de R. Fernández de Santaella, Málaga, Universidad.

LAPESA, Rafael (1987): "La Real Academia Española: pasado, realidad presente y futuro", en El español moderno y contemporáneo. Estudios lingüísticos, Barcelona, Crítica, 1996, pp. 221-237.

(1993): "Nuestra lengua en la España de 1898 a 1936", en El español moderno y contemporáneo. Estudios lingüísticos, Barcelona, Crítica, 1006, pp. 343-396. 
Morales, Carmen (2000): "Las documentaciones de los diccionarios académicos en el DCECH", $V$ Congreso Internacional de Historia de la Lengua Española, Valencia, 31 de enero al 4 de febrero de 2000. Actas en prensa.

SECO, Rafael (1995): "El diccionario histórico de la lengua española", International Journal of Lexicography, 8, pp. 203-219.

\section{APÉNDICE}

Formas que en el $D C E C H$ aparecen documentadas por primera vez (primera documentación) en una de las ediciones del DRAE

\begin{tabular}{lll} 
LEMA & $\begin{array}{l}\mathbf{1}^{\text {a }} \text { documentación } \\
\text { del DCECH }\end{array}$ & $\begin{array}{l}\mathbf{1}^{\mathbf{a}} \text { documentación } \\
\text { del DRAE }\end{array}$ \\
\hline abducción & $1884 \mathrm{Y}$ & 1884 \\
abobra & $1884 \mathrm{~F}$ & 1925 \\
abomaso & $1884 \mathrm{Y}$ & 1884 \\
abubo & $1884 \mathrm{Y}$ & 1884 \\
acalefo & $1884 \mathrm{Y}$ & 1884 \\
acarralar & $1884 \mathrm{Y}$ & 1869 \\
acarrarse & $1780 \mathrm{Y}$ & 1770 \\
aceguero & $1884 \mathrm{~F}$ & 1914 \\
acipado & $1884 \mathrm{Y}$ & 1770 \\
acleido & $1884 \mathrm{Y}$ & 1884 \\
acordeón & $1884 \mathrm{Y}$ & 1884 \\
acotar & 1780 & 1780 (Supl.) \\
ácrata & $1899 \mathrm{~F}$ & 1914 \\
acre (sust. 'medida inglesa de superficie') & $1884 \mathrm{Y}$ & 1899 \\
acrídido & $1884 \mathrm{~F}$ & 1936 (acrídidos) \\
acroamático & $1899 \mathrm{~F}$ & 1914 \\
aliadas (s. v. adehalada) & $1884 \mathrm{Y}$ & 1884 \\
adenitis & $1884 \mathrm{Y}$ & 1884
\end{tabular}

5 F detrás de la fecha indica que en el $D C E C H$ aparece la fórmula "falta en Acad..."; a su vez, la Y detrás de la fecha indica que en el $D C E C H$ aparece la fórmula "Acad. ya..."; la D detrás de la fecha indica "Acad. después de". 


\begin{tabular}{|c|c|c|}
\hline LEMA & $\begin{array}{l}1^{\text {a }} \text { documentación } \\
\text { del DCECH }\end{array}$ & $\begin{array}{l}1^{\mathrm{a}} \text { documentación } \\
\text { del DRAE }\end{array}$ \\
\hline adral & $1780 \mathrm{Y}$ & $\begin{array}{l}1770-1869 \text { (adrales) } \\
1884 \text { (adral) }\end{array}$ \\
\hline aedo & $1899 \mathrm{~F}$ & 1925 \\
\hline afaníptero & $1884 \mathrm{Y}$ & 1884 \\
\hline afasia & $1884 \mathrm{Y}$ & 1884 \\
\hline ágora & $1884 \mathrm{Y}$ & 1884 \\
\hline ajá, ajajá & $1884 \mathrm{Y}$ & 1869 \\
\hline aladroque & $1884 \mathrm{Y}$ & 1770 \\
\hline albaida & $1884 \mathrm{Y}$ & 1817 \\
\hline albardín & $1884 \mathrm{Y}$ & 1770 (albardin) \\
\hline albarrada, II & $1884 \mathrm{~F}$ & 1914 \\
\hline alboheza & $1884 Y$ & 1803 \\
\hline aldorta & $1884 \mathrm{Y}$ & 1817 \\
\hline aleatorio & $1832 F, 1884 \mathrm{Y}$ & 1869 \\
\hline alfaguara & $1884 \mathrm{Y}$ & 1884 \\
\hline alfazaque & $1884 \mathrm{Y}$ & 1817 \\
\hline alferraz & $1884 \mathrm{Y}$ & 1817 \\
\hline algavaro & $1884 \mathrm{Y}$ & 1817 \\
\hline alifa & $1869 \mathrm{Y}$ & 1817 \\
\hline alisios, vientos & $1832 \mathrm{~F}, 1884 \mathrm{Y}$ & 1843 \\
\hline alpaca, 'aleación de cobre' & $1884 \mathrm{~F}$ & 1925 \\
\hline amarilídeo & $1884 Y$ & 1884 \\
\hline amarraco & $1884 \mathrm{Y}$ & 1869 \\
\hline ambleo & $1884 \mathrm{Y}$ & 1770 \\
\hline ambón & $1884 \mathrm{Y}$ & 1884 \\
\hline amperio & $1884 \mathrm{~F}$ & 1899 \\
\hline amuso & $1884 \mathrm{~F}$ & 1925 \\
\hline anacoluto & $1884 \mathrm{~F}$ & 1936 \\
\hline analgesia & $1884 \mathrm{~F}$ & 1914 \\
\hline \multicolumn{3}{|l|}{ andaraje, 'rueda de la noria' } \\
\hline \multirow[t]{2}{*}{ 'aparato de madera' } & \multirow[t]{2}{*}{$1884 \mathrm{Y}$} & $1770\left(1^{\mathrm{a}}\right.$ ac. $)($ andarage $)$ \\
\hline & & $1884\left(2^{\mathrm{a}} \mathrm{ac}.\right)$ \\
\hline \multirow{4}{*}{$\begin{array}{l}\text { andullo, 'tejido que se pone en las } \\
\text { jaretas de los buques' } \\
\text { 'hoja de tabaco' } \\
\text { 'tamarindo envuelto en } \\
\text { hoias de plátano' }\end{array}$} & \multirow[t]{4}{*}{1770} & 1770 ('pandero') \\
\hline & & 1780 (Supl.) (2a ac.) \\
\hline & & $1899\left(1^{\mathrm{a}}\right)$ \\
\hline & & 1933-1936 (DHist. $)\left(3^{\mathrm{a}}\right.$ ac. $)$ \\
\hline
\end{tabular}




\begin{tabular}{|c|c|c|}
\hline LEMA & $\begin{array}{l}1^{\text {a }} \text { documentación } \\
\text { del DCECH }\end{array}$ & $\begin{array}{l}1^{\text {a }} \text { documentación } \\
\text { del DRAE }\end{array}$ \\
\hline angaria & $1884 \mathrm{Y}$ & 1869 \\
\hline angazo & $1884 Y$ & 1869 \\
\hline angioma & $1884 \mathrm{~F}$ & 1925 \\
\hline aniaga & $1884 \mathrm{Y}$ & 1770 \\
\hline ánodo & $1884 \mathrm{~F}$ & 1899 \\
\hline anofeles & $1884 \mathrm{~F}$ & 1936 \\
\hline antidoral & $1884 \mathrm{Y}$ & 1770 \\
\hline antílope & $1884 \mathrm{Y}$ & 1869 \\
\hline anuente & $1884 \mathrm{Y}$ & 1780 (Supl.) \\
\hline aoristo & $1884 \mathrm{Y}$ & 1884 \\
\hline apache & 1925 & 1925 \\
\hline apodíctico & $1884 Y$ & 1884 \\
\hline arandillo, 'faldellín' & $1884 Y$ & $1770\left(1^{\mathrm{a}} \mathrm{ac}.\right)$ \\
\hline 'pájaro' & & $1817\left(2^{\mathrm{a}} \mathrm{ac}.\right)$ \\
\hline arbequín & 1843F, 1936 & 1936 \\
\hline arcaico & $1884 \mathrm{Y}$ & 1869 \\
\hline argo & 1914Y & 1914 \\
\hline argonauta & $1884 Y$ & 1884 \\
\hline arjorán & $1884 \mathrm{Y}$ & 1817 (arjoran) \\
\hline armón & $1884 \mathrm{Y}$ & 1817 (armon) \\
\hline arroaz & $1884 Y$ & 1832 \\
\hline arrurruz & $1884 \mathrm{Y}$ & 1884 \\
\hline arta & $1817 Y$ & 1817 \\
\hline \multirow[t]{2}{*}{ artesiano (pozo ) } & $1884 \mathrm{Y}$ & 1843 (s.v.pozo) \\
\hline & & 1884 (s.v. artesiano) \\
\hline artocárpeo & $1884 \mathrm{~F}$ & 1899 \\
\hline \multirow[t]{2}{*}{ aspirina } & 1914F, 1936 & 1927 (DManual) \\
\hline & & 1936 \\
\hline astenia & 1884 & 1884 \\
\hline astracán & 1884F, 1925 & 1914 \\
\hline atifle & 1770 & 1770 \\
\hline atresia & $1884 \mathrm{~F}$ & 1914 \\
\hline autarquía & $1884 \mathrm{~F}$ & 1936 \\
\hline autóctono & $1884 Y$ & 1869 \\
\hline avetoro & $1884 \mathrm{~F}$ & 1914 \\
\hline azagador & $1884 Y$ & 1803 \\
\hline azoleo & $1884 \mathrm{~F}$ & 1899 \\
\hline
\end{tabular}




\begin{tabular}{|c|c|c|}
\hline LEMA & $\begin{array}{l}1^{\mathrm{a}} \text { documentación } \\
\text { del DCECH }\end{array}$ & $\begin{array}{l}1^{\text {a }} \text { documentación } \\
\text { del DRAE }\end{array}$ \\
\hline bacilo & 1899 & 1914 \\
\hline bacteria & 1899 & 1914 \\
\hline bache, II & 1770 & 1770 \\
\hline baga, I & $1817 Y$ & 1803 \\
\hline barcia & $1884 Y$ & 1884 \\
\hline bargueño & $1884 \mathrm{~F}$ & 1914 \\
\hline barí & $1884 Y$ & 1884 \\
\hline barítono & $1884 \mathrm{Y}$ & 1780 (Supl.) \\
\hline batimetría & $1936 \mathrm{Y}$ & 1936 (Supl.) \\
\hline batómetro & 1914Y & 1914 \\
\hline bayadera & 1884 & 1884 \\
\hline bayoco & $1884 Y$ & 1770 \\
\hline bencina & $1884 \mathrm{Y}$ & 1884 \\
\hline berberecho & $1832 \mathrm{~F}, 1884 \mathrm{Y}$ & 1884 \\
\hline berlanga & $1899 \mathrm{~F}$ & 1914 \\
\hline betijo & $1884 \mathrm{~F}$ & 1925 \\
\hline bímano & $1884 Y$ & 1884 (bimano) \\
\hline bimembre & $1884 \mathrm{Y}$ & 1837 (Supl.) \\
\hline birimbao & $1884 \mathrm{Y}$ & 1884 \\
\hline bis & $1884 Y$ & 1884 \\
\hline blefaritis & $1884 Y$ & 1884 \\
\hline blenorragia & $1832 \mathrm{~F}$ & 1884 \\
\hline blocao & $1884 \mathrm{Y}$ & 1884 \\
\hline bloque & $1884 \mathrm{Y}$ & 1884 \\
\hline \multirow[t]{2}{*}{ boina } & $1780 \mathrm{~F}, 1817 \mathrm{~F}$ & \\
\hline & $1832 \mathrm{~F}, 1843$ & 1843 (bóina) \\
\hline bol, I, 'ponchera' & $1884 \mathrm{Y}$ & $1869\left(1^{\mathrm{a}} \mathrm{ac}.\right)$ \\
\hline 'taza grande' & & $1925\left(2^{\mathrm{a}} \mathrm{ac}.\right)$ \\
\hline bólido & $1884 Y$ & 1884 \\
\hline borda & $1817 Y$ & 1770 \\
\hline borne, $\mathrm{V}$ (madera de $\sim$ ) & $1884 Y$ & $1884^{6}$ \\
\hline bornizo & $1899 \mathrm{~F}$ & 1914 \\
\hline
\end{tabular}

6 En el Diccionario de Autoridades aparece "Madera, cuya especie dice Covarr., es bien conocida en España. Nebrixa dice que es arbol ò madéra..."; esta redacción desaparece en 1770 sustituida por "árbol especie de roble", por lo que no tenemos suficientes motivos para determinar que madera borne apareciese ya en 1726-1739. 


\begin{tabular}{|c|c|c|}
\hline LEMA & $\begin{array}{l}1^{\text {a }} \text { documentación } \\
\text { del DCECH }\end{array}$ & $\begin{array}{l}1^{\text {a }} \text { documentación } \\
\text { del DRAE }\end{array}$ \\
\hline boxear & $1899 \mathrm{~F}$ & $\begin{array}{l}1927 \text { (DManual) } \\
1936 / 47\end{array}$ \\
\hline brasca & $1884 \mathrm{~F}$ & 1925 \\
\hline branquia & 1832F, 1884 & 1884 \\
\hline braznar & 1780 (Supl.) & 1780 (Supl.) \\
\hline bricbarca & $1884 Y$ & 1884 (brigbarca) \\
\hline brilla & $1884 \mathrm{~F}$ & 1925 \\
\hline bromatología & $1884 \mathrm{Y}$ & 1884 \\
\hline buganvilla & $1884 \mathrm{~F}$ & $1936 / 47$ \\
\hline bugle & 1884D & $1936 / 47$ \\
\hline bulimia & $1884 \mathrm{Y}$ & 1884 \\
\hline burlete & $1884 \mathrm{Y}$ & 1884 \\
\hline bustrófedon & $1884 \mathrm{Y}$ & 1884 \\
\hline butaca & 1843 & 1843 \\
\hline butomeo & $1884 \mathrm{~F}$ & 1899 \\
\hline cabila & $1884 \mathrm{~F}$ & 1899 \\
\hline cabruñar & $1884 \mathrm{Y}$ & 1884 \\
\hline cacatúa & $1884 \mathrm{~F}$ & 1899 \\
\hline cacodilo & $1884 \mathrm{~F}$ & 1925 \\
\hline cafería & $1884 \mathrm{~F}$ & 1884 (Supl.) \\
\hline calabre & $1884 \mathrm{Y}$ & 1780 \\
\hline calamistro & $1884 \mathrm{~F}$ & 1925 \\
\hline calántica & $1884 \mathrm{~F}$ & 1925 \\
\hline cálido, II & $1884 \mathrm{Y}$ & 1780 \\
\hline cambrillón & $1884 \mathrm{~F}$ & 1925 \\
\hline cancho & $1884 \mathrm{Y}$ & 1884 \\
\hline canterio & 1936 ó 1925 & 1925 (canterios) \\
\hline capuana & 1843F, 1884 & 1884 \\
\hline caqui & $1899 \mathrm{~F}$ & 1925 \\
\hline carló & $1884 \mathrm{~F}$ & 1925 \\
\hline cartolas o artolas & $1884 Y$ & 1822 (Supl.) \\
\hline casida & $1884 \mathrm{~F}$ & 1925 \\
\hline casitéridos & $1884 \mathrm{~F}$ & 1925 \\
\hline casuario & $1899 \mathrm{Y}$ & 1899 \\
\hline \multirow[t]{2}{*}{ cayutana } & $1884 \mathrm{~F}$ & 1927 (DManual) \\
\hline & & $1936 / 1947$ \\
\hline
\end{tabular}




\begin{tabular}{|c|c|c|}
\hline LEMA & $\begin{array}{l}1^{\text {a }} \text { documentación } \\
\text { del DCECH }\end{array}$ & $\begin{array}{l}1^{\text {a documentación }} \\
\text { del DRAE }\end{array}$ \\
\hline celán & 1925 & 1925 \\
\hline célere & $1884 Y$ & 1884 \\
\hline cemento (s. v. cimiento) & $1884 \mathrm{Y}$ & 1884 \\
\hline cerámica & 1869 & 1869 \\
\hline cereal & 1822 & 1822 (Supl.) \\
\hline cestodos & $1884 \mathrm{~F}$ & $1936 / 47$ \\
\hline cícero & 1899 & 1899 \\
\hline cicerone (s. v. cícero) & $1899 \mathrm{~F}$ & 1869 \\
\hline cicindela & $1899 \mathrm{~F}$ & 1925 \\
\hline cifosis & $1899 \mathrm{~F}$ & 1925 (cifosis y sifosis) \\
\hline cigomático & $1884 Y$ & 1884 \\
\hline cinglar & $1899 \mathrm{~F}$ & 1925 \\
\hline cingleta & $1899 Y$ & 1899 \\
\hline cipayo & $1884 Y$ & 1869 \\
\hline ciperáceo & 1899 & 1899 \\
\hline cistíneo & 1899 & 1899 \\
\hline civeta & 1843F, 1884 & 1884 \\
\hline clac & $1884 \mathrm{Y}$ & 1884 \\
\hline cladodio & 1899 & 1899 \\
\hline clan & $1899 \mathrm{~F}$ & 1925 \\
\hline clarens & $1899 \mathrm{~F}$ & 1925 \\
\hline cleda & 1899 & 1899 \\
\hline clica & $1899 \mathrm{~F}$ & $1936 / 47$ \\
\hline clínico & $1884 \mathrm{Y}$ & 1869 (adj. y sust.) \\
\hline clisé & $1884 Y$ & 1869 \\
\hline cloro & $1884 Y$ & 1852 \\
\hline cobez & $1899 \mathrm{~F}$ & 1925 \\
\hline coca, II & $1817 \mathrm{Y}$ & 1780 \\
\hline $\begin{array}{l}\text { coca, III, 'vuelta que toma un cabo } \\
\text { por vicio de torsión' }\end{array}$ & $1884 \mathrm{Y}$ & 1869 \\
\hline coco, III & $1899 \mathrm{~F}$ & $1936 / 47$ \\
\hline codeína & $1884 \mathrm{Y}$ & 1884 \\
\hline codena & 1817 & 1780 \\
\hline codón & $1899 \mathrm{~F}$ & $1936 / 47$ \\
\hline cohobar & $1843 \mathrm{~F}, 1884 \mathrm{Y}$ & 1869 \\
\hline cola, III & $1899 \mathrm{~F}$ & 1925 \\
\hline coleóptero & 1843F, 1884Y & 1869 \\
\hline
\end{tabular}




\begin{tabular}{|c|c|c|}
\hline LEMA & $\begin{array}{l}1^{\text {a }} \text { documentación } \\
\text { del DCECH }\end{array}$ & $\begin{array}{l}1^{\text {a }} \text { documentación } \\
\text { del DRAE }\end{array}$ \\
\hline colimación & $1899 \mathrm{~F}$ & $\begin{array}{l}1927 \text { (DManual) } \\
1936 / 47\end{array}$ \\
\hline colofón & $1843 F, 1884 Y$ & 1884 \\
\hline $\begin{array}{l}\text { colla, 'conjunto de nasas colocadas } \\
\text { encima...' }\end{array}$ & $1899 \mathrm{~F}$ & $1914\left(1^{\mathrm{a}} \mathrm{ac}.\right)$ \\
\hline 'un par de perros atraillados' & & $1925\left(2^{\mathrm{a}}\right.$ ac. $)$ \\
\hline 'última estopa...' & & $1925\left(3^{\mathrm{a}}\right.$ ac. $)$ \\
\hline coma, II & $1843 \mathrm{~F}, 1884$ & 1884 \\
\hline coma, IV & $1843 F, 1884$ & 1884 \\
\hline comistrajo & $1783 \mathrm{Y}$ & 1780 \\
\hline comiza & 1783 & 1780 \\
\hline comodoro & $1843 F, 1884$ & 1869 \\
\hline comto & $1899 \mathrm{~F}$ & 1925 \\
\hline concia & $1843 F, 1884$ & 1884 \\
\hline cóndilo & $1843 F, 1884$ & 1869 \\
\hline condón & $1936-1939 \mathrm{~F}$ & $\begin{array}{l}1989 \text { (DManual) } \\
1992\end{array}$ \\
\hline connivente & $1899 \mathrm{~F}$ & $\begin{array}{l}1927 \text { (DManual) } \\
1936 / 47\end{array}$ \\
\hline consola & $1843 F, 1884$ & 1869 \\
\hline coñac & 1914 & 1914 \\
\hline $\begin{array}{l}\text { copar, 'cortar la retirada a una } \\
\text { fuerza militar', } \\
\text { 'hacer en los juegos de azar } \\
\text { una puesta...', } \\
\text { 'conseguir en una elección } \\
\text { todos los puestos' }\end{array}$ & 1843F, 1884 & $\begin{array}{l}1852\left(1^{\mathrm{a}} \text { y } 2^{\mathrm{a}} \text { acs. }\right) \\
1925\left(3^{\mathrm{a}} \text { ac. }\right)\end{array}$ \\
\hline coque & $1884 \mathrm{~F}$ & 1899 \\
\hline cora & 1843F, 1884 & 1884 \\
\hline corimbo & $1843 \mathrm{~F}, 1884$ & 1869 \\
\hline corindón & 1843F, 1884 & 1869 (corindon) \\
\hline cormiera & $1899 \mathrm{~F}$ & 1925 \\
\hline cornaca & 1843F, 1884 & 1884 \\
\hline corónide & $1899 \mathrm{~F}$ & $\begin{array}{l}1927 \text { (DManual) } \\
1936 / 47\end{array}$ \\
\hline coruscar & 1843F, 1884 & 1884 \\
\hline cosmos & 1843F, 1884 & 1884 \\
\hline
\end{tabular}




\section{LEMA}

cotillón, 'danza con figuras en bailes
$\quad$ de sociedad'
cotillón, 'baile de sociedad'
cotofre
coy
cran
cráter
crátera (s. v. cráter)
crecal
cremación
cremallera
crematístico
creosota
cretino
cretona
cric (s. v. crica)
cricoides
cromo
croquis
crup
cuarzo
cuasia
cuchipanda
cuché, (papel $~$

$1^{a}$ documentación $\quad 1^{\text {a documentación }}$ del DCECH del DRAE

\begin{tabular}{|c|c|}
\hline $1843 \mathrm{~F}, 1884 \mathrm{Y}\left(1^{\mathrm{a}} \mathrm{ac}.\right)$ & $\begin{array}{l}1884\left(1^{\mathrm{a}} \text { ac. }\right) \\
1936 \mathrm{~F}\left(2^{\mathrm{a}} \text { ac. }\right) \\
1984\left(2^{\mathrm{a}} \text { ac. }\right)\end{array}$ \\
\hline $1783 Y$ & 1780 \\
\hline 1817F, 1843Y & $1791(\mathrm{coi})$ \\
\hline 1843F, 1884 & 1884 \\
\hline 1817F, 1843 & 1832 \\
\hline $1899 \mathrm{~F}$ & 1925 \\
\hline 1899F & 1925 \\
\hline 1843F, 1884Y & 1884 \\
\hline 1843F, 1884Y & 1884 \\
\hline $1899 \mathrm{~F}$ & 1925 \\
\hline $1843 \mathrm{~F}, 1884 \mathrm{Y}$ & 1884 \\
\hline $1843 F, 1884 Y$ & 1884 \\
\hline $1843 \mathrm{~F}, 1884 \mathrm{Y}$ & 1884 \\
\hline $1843 \mathrm{~F}, 1884 \mathrm{Y}$ & 1884 \\
\hline $1899 \mathrm{~F}$ & $\begin{array}{l}1927 \text { (DManual) } \\
1936\end{array}$ \\
\hline 1843F, 1884 & 1869 \\
\hline $1817 \mathrm{~F}, 1843$ & 1832 \\
\hline $1843 \mathrm{~F}, 1884 \mathrm{Y}$ & 1884 \\
\hline $1843 \mathrm{Y}$ & 1817 (Supl.) \\
\hline $1899 \mathrm{~F}$ & 1925 \\
\hline $1843 \mathrm{~F}, 1884$ & 1884 \\
\hline $1899 \mathrm{~F}$ & 1925 (s.v. papel) \\
\hline & 1927 (DManual, s.v.cuché) \\
\hline & 1936 (s.v. cuché) \\
\hline $1899 \mathrm{~F}$ & 1925 \\
\hline 1899Y & 1899 (Supl.) \\
\hline $1899 \mathrm{~F}$ & 1936 \\
\hline 1843F, 1884 & 1852 (cupon) \\
\hline $1843 \mathrm{Y}$ & 1803 (Supl.) \\
\hline $1843 \mathrm{Y}$ & 1780 \\
\hline $1843 Y$ & 1832 \\
\hline $1843 \mathrm{Y}$ & 1837 \\
\hline $1899 \mathrm{~F}$ & 1927 (DManual) \\
\hline & $1936 / 47$ \\
\hline $1899 \mathrm{~F}$ & 1914 \\
\hline
\end{tabular}

